\title{
A Systematic Review of Osteoporosis Health Beliefs in Adult Men and Women
}

\author{
Katherine M. McLeod ${ }^{1}$ and C. Shanthi Johnson ${ }^{1,2}$ \\ ${ }^{1}$ Faculty of Kinesiology and Health Studies, University of Regina, 3737 Wascana Pkwy, Regina, Sk, Canada S4S OA2 \\ ${ }^{2}$ Saskatchewan Population Health and Evaluation Research Unit, University of Regina, Regina, Sk, Canada S4S OA2
}

Correspondence should be addressed to C. Shanthi Johnson, shanthi.johnson@uregina.ca

Received 30 May 2011; Accepted 13 July 2011

Academic Editor: David L. Kendler

Copyright ( $\odot 2011$ K. M. McLeod and C. S. Johnson. This is an open access article distributed under the Creative Commons Attribution License, which permits unrestricted use, distribution, and reproduction in any medium, provided the original work is properly cited.

Osteoporosis is major public health concern affecting millions of older adults worldwide. A systematic review was carried out to identify the most common osteoporosis health beliefs in adult men and women from descriptive and intervention studies. The Osteoporosis Health Belief Scale (OHBS) and Osteoporosis Self-efficacy Scale (OSES) evaluate osteoporosis health beliefs, including perceived susceptibility and seriousness, benefits, barriers, and self-efficacy of calcium and exercise, and health motivation, and their relationship to preventive health behaviours. A comprehensive search of studies that included OHBS and OSES subscale scores as outcomes was performed. Fifty full-text articles for citations were reviewed based on inclusion criteria. Twenty-two articles met the inclusion criteria. Greater perceived seriousness, benefits, self-efficacy, health motivation, and fewer barriers were the most common health-belief subscales in men and women. Few studies were interventions $(n=6)$ and addressed osteoporosis health beliefs in men $(n=8)$. Taking health beliefs into consideration when planning and conducting education interventions may be useful in both research and practice for osteoporosis prevention and management; however, more research in this area is needed.

\section{Introduction}

Affecting nearly two million Canadians, osteoporosis is a progressive skeletal disease that can be largely prevented and managed through health behaviours such as adequate calcium and vitamin D intake, timely diagnosis, and costeffective treatment [1]. Fragility fractures, the consequence of osteoporosis, have profound effects. Among the most devastating are hip fractures with approximately 30,000 occurring yearly in Canada and the prevalence of vertebral deformities, which typically represent vertebral fractures, is seen in $21.5 \%$ of men and $23.5 \%$ of women over 50 years of age $[2,3]$. These fractures reduce individuals' quality of life and are associated with a 3 -fold increased risk of death within five years compared to those that do not suffer fracture [4]. In addition, fragility fractures are a major financial burden for Canada's health care system with estimated total health care costs reaching $\$ 1.9$ billion annually [1].

Current research suggests that many individuals with fragility fracture do not undergo appropriate screening or treatment and do not engage in preventive health behaviours $[5,6]$. Evaluating the structural and psychological determinants of health behaviour is important in order to better understand and manage the disease. Rosenstock's Health Belief Model (HBM) is one of the most widely used psychosocial frameworks in health behaviour research and practice [7]. It is also the most widely applied conceptual framework for evaluating osteoporosis health beliefs and their relationship to osteoporosis-related health behaviours $[7,8]$. The HBM suggests that an individual's health beliefs are associated with the likelihood of engaging in health behaviours. The premise of the HBM is that an individual's actions to prevent, screen for, or manage disease depends on the following constructs: (a) perceived susceptibility, (b) perceived seriousness, (c) perceived benefits of a behaviour, (d) perceived barriers to a behaviour, (e) cues to action including events that motivate individuals to take action, and (f) self-efficacy. The self-efficacy construct was later introduced to the HBM by Rosenstock et al. [9] with the intent to better predict factors associated with changing health 
behaviours. Modifying factors such as demographics, sociopsychological variables, and socioeconomic status may also influence perceptions, and thus indirectly influence health behaviours [10]. Since its development, a wide diversity of populations, health conditions, and health behaviours have been measured using the HBM. A systematic review, by Harrison et al., determined the relationship between the HBM constructs and health behaviour of 16 studies, none of which related to osteoporosis [11]. Results of weighted mean effect sizes showed susceptibility, seriousness, barriers, and benefits were significant predictors of health behaviours. However, it is important to acknowledge that the same underlying construct may not always be measured in every study. Health beliefs may vary depending on health condition and should not be generalized. Therefore, it is important that construct definitions are consistent with the original HBM theory, but that measures are specific to the health behaviour and population being addressed. For example, barriers to osteoporosis screening may be different from barriers to colonoscopy.

In 1991, Kim et al. developed the Osteoporosis Health Belief Scale (OHBS), based on the HBM, to evaluate health beliefs related to osteoporosis and determine the relationship between health beliefs and osteoporosis preventive health behaviours including calcium intake and exercise [12]. The OHBS is a 42-item questionnaire developed and validated in 201 women ages 35 to 95 years. The 42 items are separated into seven subscales: perceived susceptibility to osteoporosis, perceived seriousness of osteoporosis, general health motivation, benefits and barriers to calcium intake, and benefits and barriers to exercise. Cues to action were not included in the OHBS as it is a difficult construct to translate into a clearly defined measure in order to have theoretical coherence. The OHBS is rated using a 5-point Likert scale (1 $=$ strongly disagree, $5=$ strongly agree). The possible range of scores for each subscale is 6 to 30 with a possible total score range from 42 to 210 . Cronbach's alpha for both subscales ranged from .61 to .80 .

Although the OHBS did not measure self-efficacy, the Osteoporosis Self-Efficacy Scale (OSES) was subsequently developed in 1998 by Horan et al. to evaluate self-efficacy of behaviours related to exercise and calcium intake [13]. The OSES (12-item and 21-item versions) was developed and validated in the same study sample as the OHBS. Each version has two subscales: the Osteoporosis Self-Efficacy(OSE-) Exercise scale (6 or 10 items) and the Osteoporosis Self-Efficacy- (OSE-) Calcium scale (6 or 11 items). A $100 \mathrm{~mm}$ visual analog scale is used to rate confidence in performing exercise and calcium intake $(0=$ not at all confident, $100=$ very confident). Scores range from 0 to 100 . Results showed the OSE-Exercise and OSE-Calcium scales had internal consistency estimates of .90 for both scales of the 12 -item version, and .94 and .93, respectively, for the 21item version.

Since their development, several studies have applied the OHBS and OSES to both men and women in a variety of age groups. At least one in four women and one in eight men over 50 years of age suffer from osteoporosis, thus health beliefs related to the disease may be different among men and women of this age group compared to younger adults [1]. Gaining a better understanding of osteoporosis health beliefs in the older adult population may provide useful information for targeting key constructs of health belief perceptions when developing interventions to improve osteoporosis prevention and management. The purpose of this systematic review was to identify the most common osteoporosis health beliefs, as measured by the OHBS and OSES, in adult men and women from both descriptive and intervention studies. Differences in osteoporosis health beliefs among gender and age groups were examined.

\section{Methods}

The literature search using multiple databases (Medline, PsycINFO, and the Cochrane Database) was conducted to identify descriptive and intervention studies using the OHBS and/or OSES published from 1991 to December 2010. The literature published prior to 1991 was not included as the OHBS and OSES were developed, respectively, in 1991 and 1998. The search strategy included the following keywords to identify primary articles: osteoporosis health beliefs, osteoporosis health belief scale, osteoporosis selfefficacy, and osteoporosis self-efficacy scale.

Titles and abstracts of all identified citations from the literature search were screened, and the reference lists of all primary articles were examined to identify other relevant publications. From the literature search, citations of articles identified as potentially suitable for inclusion were exported to reference software, EndNote $\mathrm{X}$ for Windows 7, for reference management. Full-text articles for the citations were retrieved and two reviewers (K. McLeod and N. Bonsu) independently evaluated the methodology, results, and discussion sections based on the following inclusion criteria (Figure 1): (1) Population: adult men and women (mean age $\geq 18$ yrs); (2) focus: osteoporosis; (3) outcomes: OHBS and OSES subscale scores; (4) study design: descriptive and intervention studies. Articles were also limited to English language. Articles using the OHBS and/or OSES to measure health beliefs but did not report quantitative results were excluded. A total of 72 potentially relevant articles were identified and screened. Of these, 50 articles were excluded as summarized in Figure 1. The level of agreement between the two reviewers was $89 \%$. The first reviewer chose to include 24 articles, while the second reviewer selected 27 articles based on inclusion criteria. Inconsistencies between the reviewers regarding the selection of articles meeting defined inclusion criteria were resolved in a consensus meeting and a decision was made to exclude seven articles.

Data abstraction and synthesis of the final set of articles selected in the review were based on the research question and included evaluation of study design and intervention, population, and OHBS and OSES subscale scores. Using a standardized table, data was extracted based on the study design (descriptive or intervention, method of randomization, and type of intervention), population characteristics (gender, sample size, and age), OHBS subscale scores (susceptibility, seriousness, benefits and barriers to calcium intake and exercise, health motivation, and total scores), and 


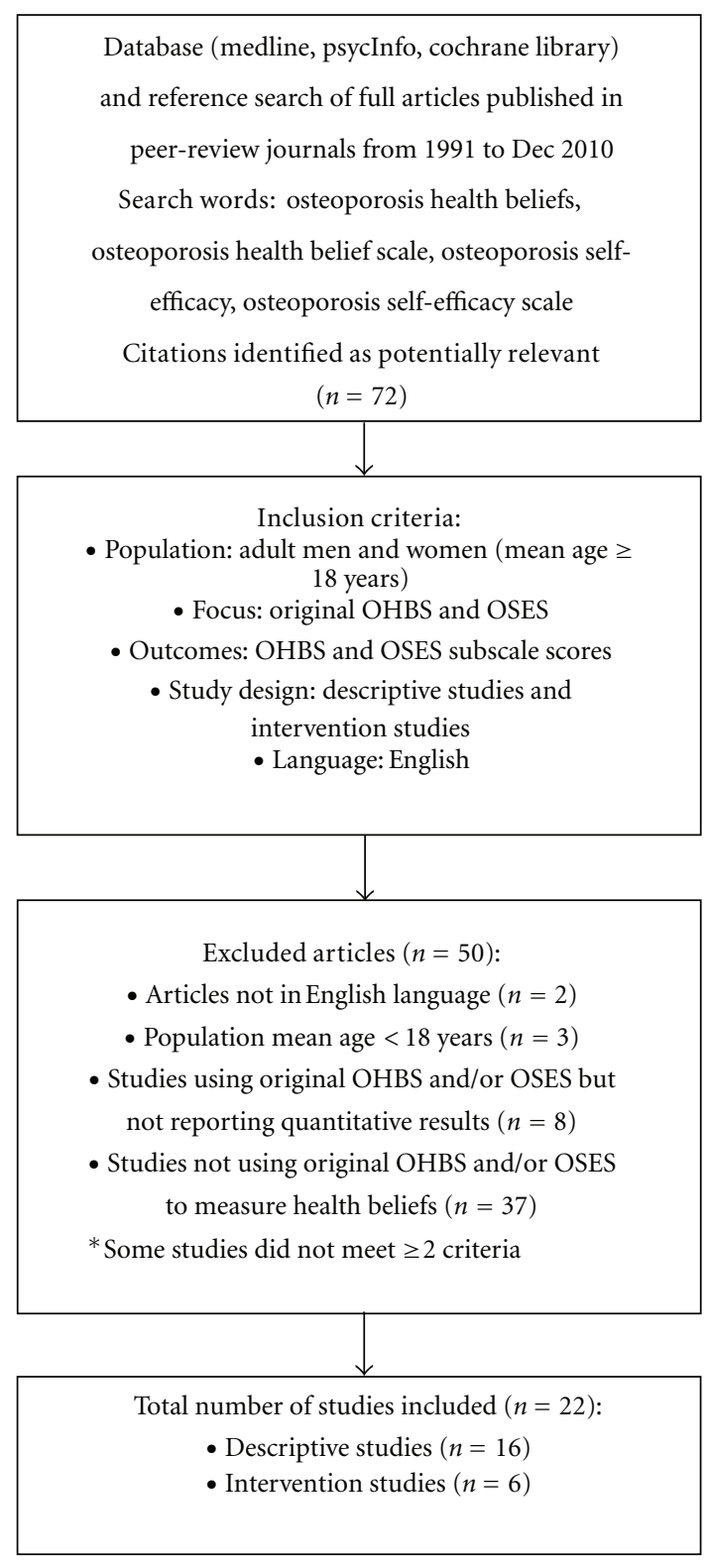

FIGURE 1: Flowchart summarizing the search process and study identification.

OSES subscale scores (self-efficacy of calcium intake and exercise and total scores) were entered for further synthesis. The data was reviewed and differences in study quality, participants, interventions, and outcomes were noted.

\section{Results}

A total of 22 articles representing 4903 men and women were included in the final set of articles for review (Figure 1). Six articles were intervention studies, of which five were randomized controlled trials, assessing health belief outcomes using both the OHBS and OSES [14-19]. The majority of the studies were descriptive $(n=16)$, of which 14 used the OHBS and 10 used the OSES to assess health beliefs
[20-35]. Only seven descriptive studies [24-26, 28-30, 34] and one intervention study [18] assessed men's health beliefs using the OHBS and OSES, and the majority of studies had a study population with mean age $\geq 45$ years $[15,16,19$ $21,23,24,26-32]$.

3.1. Descriptive Study Outcomes. The OHBS subscale results for descriptive studies are shown in Table 1. Based on the defined OHBS subscale score range (6 to 30), overall scores for perceived susceptibility were low to moderately high, ranging, respectively, from 8.6 to 19.5. Perceived seriousness scores were moderate to high (13.8 to 20.2). Scores for perceived benefits of calcium intake (21.2 to 25.5) and exercise (21.9 to 25.9$)$ were high, while perceived barriers to calcium intake (10.7 to 15.6 ) and exercise (9.9 to 15.3 ) were much lower. Health motivation scores (15.0 to 24.8) were moderate to high overall (Table 1) [21-29, 32, 33]. A closer assessment of the results in men and women showed women appear to have greater perceived susceptibility to osteoporosis, greater perceived benefits of calcium intake, fewer perceived barriers to calcium intake, and less health motivation compared to men [21, 23-29, 32, 33].

Regarding age differences, men and women $\geq 45$ years of age appear to have greater perceived susceptibility to osteoporosis (11.4 to 19.5), greater perceived seriousness of the disease (14.8 to 19.4), and greater perceived barriers to calcium intake (12.3 to 15.6 ) and exercise (11.3 to 15.3) compared to men and women $<45$ years of age [21, 23$29,32]$. Only one study evaluated calcium and exercise benefits and barriers in younger adults (mean age 28.34 years) and grouped results based on women's calcium intake $(\geq 1200 \mathrm{mg} /$ day or $<1200 \mathrm{mg} /$ day) and exercise $(\geq 90 \mathrm{~min} / \mathrm{wk}$ or $<90 \mathrm{~min} / \mathrm{wk}$ ) [33]. Regardless grouping, scores for perceived benefits of calcium intake and exercise were high ( $>21.00$ ), as were those in individuals $\geq 45$ years of age $[21,24-27,29,33]$. Similarly, two studies involving older men and women provided scores on a scale of one to five and showed moderately high-perceived susceptibility to osteoporosis, and high-perceived benefits to calcium, exercise, as well as health motivation [20,31].

Table 2 presents results of the OSES subscales for descriptive studies. In studies using the 12- and 21-item OSES subscales with scores ranging 0 to 100 , subscale scores for women ranged from 60.6 to 79.9 for OSE-calcium and 48.5 to 83.8 for OSE-exercise (Table 2). Overall, self-efficacy of calcium intake and exercise was moderately high, however, those reporting low calcium intake $(<1200 \mathrm{mg} /$ day $)$ and exercise ( $<90 \mathrm{~min} / \mathrm{wk})$ had self-efficacy scores far lower than those reporting high calcium intake $(\geq 1200 \mathrm{mg} /$ day $)$ and exercise ( $\geq 90 \mathrm{~min} / \mathrm{wk}$ ) [33]. Men appear to have greater selfefficacy in performing exercise (66.9 to 84.5) compared to women $(48.5$ to 83.8$)[25,26,30,31,33,34]$, and this was found to be statistically significant $(P<0.05)$ in the study by Doheny et al. [24].

With regard to age, men and women $\geq 45$ years appear to have similar self-efficacy of calcium intake. Using the OSES 12 -item subscale with score ranges from 0 to 600 , self-efficacy of calcium intake appears to be lower (406.9 to 438.5) among young college sophomores and seniors compared to men and 


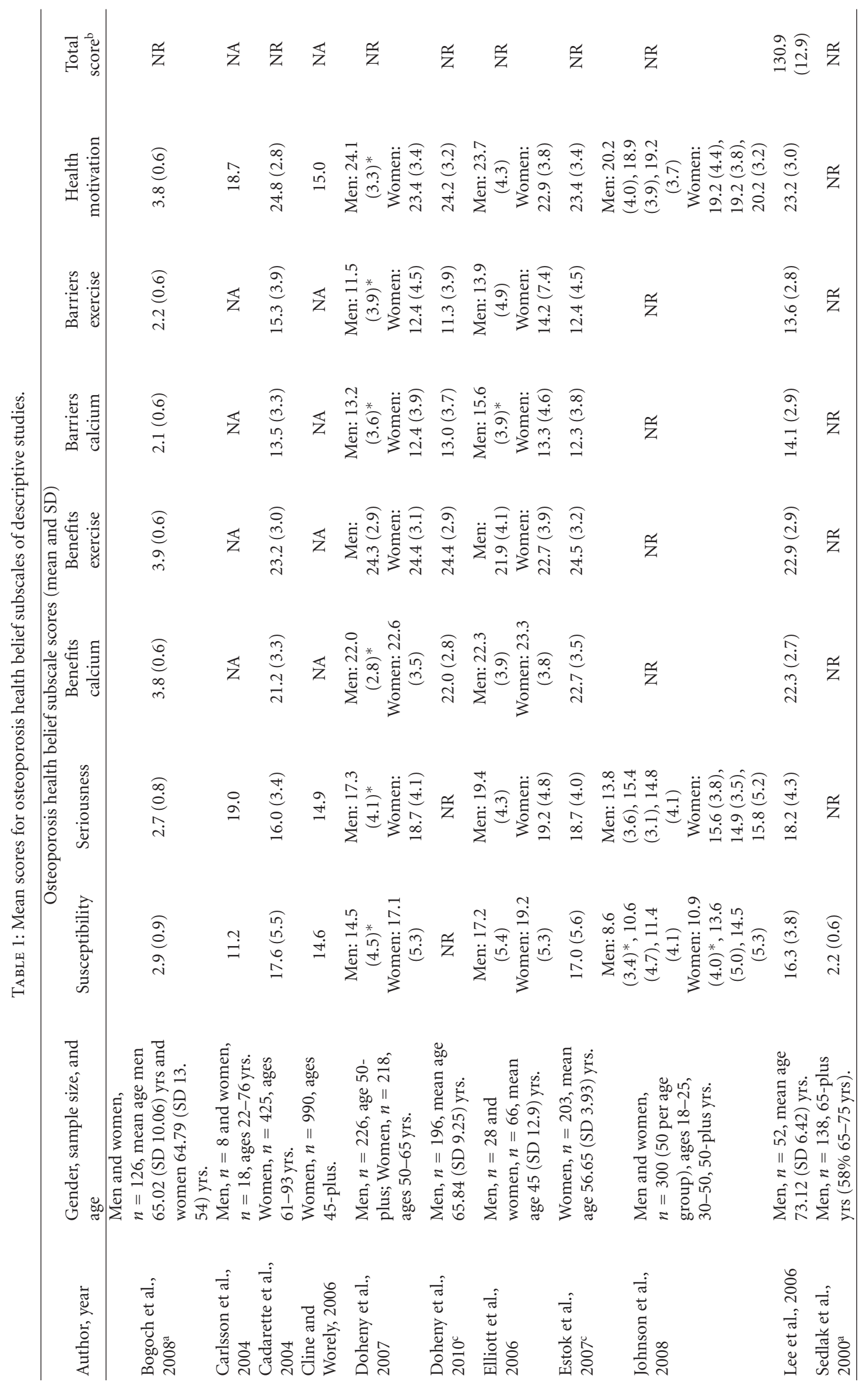




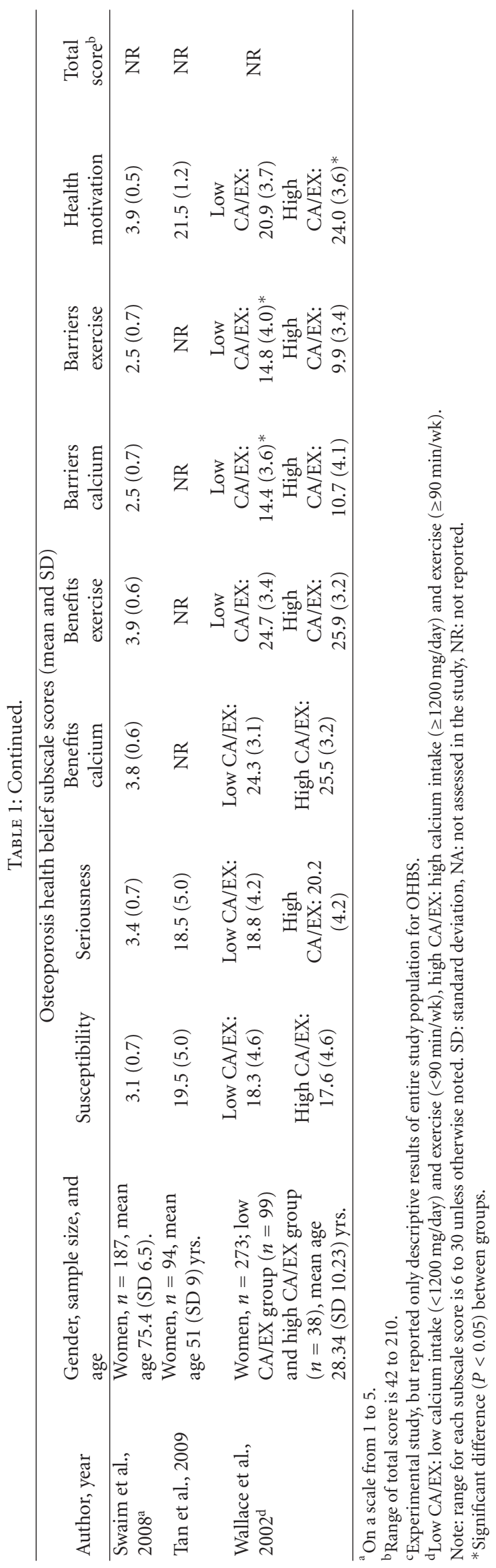


TABLE 2: Mean scores for osteoporosis self-efficacy subscales of descriptive studies.

\begin{tabular}{|c|c|c|c|c|}
\hline \multicolumn{5}{|c|}{ Osteoporosis self-efficacy subscale scores (mean and SD) } \\
\hline Author, year & Gender, sample size, and age & $\begin{array}{l}\text { Self-efficacy } \\
\text { calcium }\end{array}$ & Self-efficacy exercise & Total score ${ }^{\mathrm{d}}$ \\
\hline $\begin{array}{l}\text { Bogoch et al., } \\
2008^{\text {a }}\end{array}$ & $\begin{array}{l}\text { Men and women, } n=114 \text {, mean age men } 65.02 \text { (SD } \\
10.06) \text { yrs and women } 64.79 \text { (SD 13.54) yrs. }\end{array}$ & $65.9(26.9)$ & $81.6(16.9)$ & NR \\
\hline \multirow{2}{*}{$\begin{array}{l}\text { Doheny et al., } \\
2007^{c}\end{array}$} & \multirow{2}{*}{$\begin{array}{l}\text { Men, } n=226 \text {, age } 50 \text {-plus; Women, } n=218 \text {, ages } \\
50-65 \text { yrs. }\end{array}$} & Men: $462.9(111.6)$ & Men: $453.4(128.7)^{*}$ & \multirow{2}{*}{ NR } \\
\hline & & $\begin{array}{l}\text { Women: } 460.6 \\
\quad(127.0)\end{array}$ & Women: $402.0(138.0)$ & \\
\hline $\begin{array}{l}\text { Doheny et al., } \\
2010^{c}\end{array}$ & Men, $n=196$, mean age 65.84 (SD 9.25) yrs. & $77.0(17.7)$ & $75.6(20.6)$ & NR \\
\hline \multirow{2}{*}{ Elliott et al., 2006 } & \multirow{2}{*}{$\begin{array}{l}\text { Men, } n=28 \text { and women, } n=66 \text {, mean age } 45 \text { (SD } \\
\text { 12.9) yrs. }\end{array}$} & Men: $67.4(27.4)$ & Men: $73.3(24.0)$ & \multirow{2}{*}{ NR } \\
\hline & & $\begin{array}{l}\text { Women: } 71.9 \\
(26.7)\end{array}$ & Women: $63.4(25.4)$ & \\
\hline Estok et al., $2007^{\mathrm{c}}$ & Women, $n=203$, mean age 56.65 (SD 3.93) yrs. & $459.6(128.5)$ & $402.6(138.6)$ & NR \\
\hline \multirow{2}{*}{$\begin{array}{l}\text { Gammage et al., } \\
2009^{\text {b }}\end{array}$} & \multirow{2}{*}{ Men, $n=176$ and women, $n=351$ ages $17-21$ yrs. } & Men: $75.4(19.0)$ & Men: 84.5 (13.9) & \multirow[t]{2}{*}{ NR } \\
\hline & & $\begin{array}{l}\text { Women: } 73.5 \\
(18.3)\end{array}$ & Women: 77.8 (15.1) & \\
\hline Sedlak et al., $2000^{\mathrm{a}}$ & Men, $n=138$, 65-plus yrs (58\% 65-75 yrs) & $67.7(24.6)$ & $66.9(25.1)$ & NR \\
\hline Swaim et al., 2008 a & Women, $n=187$, mean age $75.4($ SD 6.5$)$ & $69.4(28.8)$ & $76.7(23.8)$ & NR \\
\hline \multirow{2}{*}{$\begin{array}{l}\text { Wallace et al., } \\
2002^{\mathrm{a}, \mathrm{f}}\end{array}$} & \multirow{2}{*}{$\begin{array}{l}\text { Women, } n=273 \text {; Low CA/EX group }(n=99) \text { and high } \\
\text { CA/EX group }(n=38) \text {, mean age } 28.34(\text { SD } 10.23) \text { yrs }\end{array}$} & $\begin{array}{l}\text { Low CA/EX: } 60.6 \\
(22.2)\end{array}$ & $\begin{array}{l}\text { Low CA/EX: } 48.5 \\
(26.6)\end{array}$ & \multirow[t]{2}{*}{ NR } \\
\hline & & $\begin{array}{l}\text { High CA/EX: } 79.9 \\
(18.6)^{*}\end{array}$ & $\begin{array}{l}\text { High CA/EX: } 83.8 \\
\qquad(14.6)^{*}\end{array}$ & \\
\hline \multirow[t]{2}{*}{$\begin{array}{l}\text { Ziccardi et al., } \\
2004^{\mathrm{c}}\end{array}$} & \multirow{2}{*}{$\begin{array}{l}\text { Men }(n=11) \text { and women }(n=183) \text { college } \\
\text { sophomores }(n=86) \text { and seniors }(n=108) \text {, mean age } \\
22.8 \text { yrs for sophomores, } 24.8 \text { yrs for seniors }\end{array}$} & Sophomores: 406.9 & Sophomores: 367.3 & \multirow{2}{*}{$\begin{array}{l}\text { Sophomores: } \\
\quad 774.2 \\
\text { Seniors: } 850.5^{*}\end{array}$} \\
\hline & & Seniors: 438.5 & Seniors: $412.1^{*}$ & \\
\hline \multicolumn{5}{|c|}{$\begin{array}{l}\text { a } 12 \text {-item subscale used; score ranges from } 0 \text { to } 100 . \\
\text { b21-item subscale used; score ranges from } 0 \text { to } 100 \text {. } \\
\text { c } 12 \text {-item subscale used; score ranges from } 0 \text { to } 600 \text {. } \\
{ }^{\mathrm{d}} \text { Range of total score for } 12 \text {-item and } 21 \text {-item questionnaire is } 0 \text { to } 1200 \text { and } 0 \text { to } 2100 \text {, respectively. } \\
\text { } \text { Experimental study, but reported only descriptive results of entire study population for OSES. } \\
\text { f Low CA/EX: low calcium intake }(<1200 \mathrm{mg} / \text { day) and exercise }(<90 \mathrm{~min} / \mathrm{wk}) \text {, high CA/EX: high calcium intake }(\geq 1200 \mathrm{mg} / \text { day) and exercise ( } \geq 90 \mathrm{~min} / \mathrm{wk}) \text {. } \\
\text { Note: SD: standard deviation, DXA: dual X-ray absorptiometry, NA: not assessed in the study, NR: not reported. } \\
\text { * Significant difference }(P<0.05) \text { between groups. }\end{array}$} \\
\hline
\end{tabular}

women over 50 years of age (459.6 to 462.9$)$ [24, 27, 35]. Additionally, self-efficacy of exercise appears to be higher in older men compared to younger adults $[24,35]$.

3.2. Intervention Study Outcomes. Three of the six trials used osteoporosis education as the intervention $[14,17$, 18], one used dual X-ray absorptiometry (DXA) screening [16], and one used education and DXA combined [15]. The one group pretest-posttest study used education, DXA, and counselling as the intervention [19]. The osteoporosis education interventions varied in length and content. Two trials administered a three-hour education program [14, 17] and one trial a two-hour education program [18] consisting of group discussion, demonstrations, and lectures pertaining to osteoporosis prevention and management. One study performed a tailored telephone-based education session addressing the individuals' DXA results, knowledge of osteoporosis, and participation in health behaviours [15], and one administered a 90-minute education session once a week for four weeks, using the OHBS and OSES as a framework [19]. It is important to note that only two trials and the one group pretest-posttest study reported results for more than two OHBS subscales [14, 17, 19], and only two trials reported OSES subscale scores, highlighting the need for more experimental research in this area [14, 17]. Meta-analysis of the five randomized controlled trials was not performed because of methodological and clinical heterogeneity, particularly in study quality, participants, intervention type, and outcomes of OHBS and OSES.

Table 3 shows OHBS subscale results for the intervention studies. Three trials reported scores of perceived susceptibility in women, ranging from 18.1 to 26.1 in the treatment group and from 12.8 to 17.4 in the control group [14, 16, 17]. Piaseu et al. [14] and Sedlak et al. [16] found a statistically significant difference $(P<0.05)$ between these groups. Piaseu et al. [14] also found that young women (mean age 19 years) were significantly more likely to perceive osteoporosis as serious, perceive benefits to exercise and greater barriers to calcium intake and exercise, and have greater health motivation after a three-hour education program compared to those in the control group $(P<0.05)$. In a different trial of women primarily 18 to 19 years of age carried out 


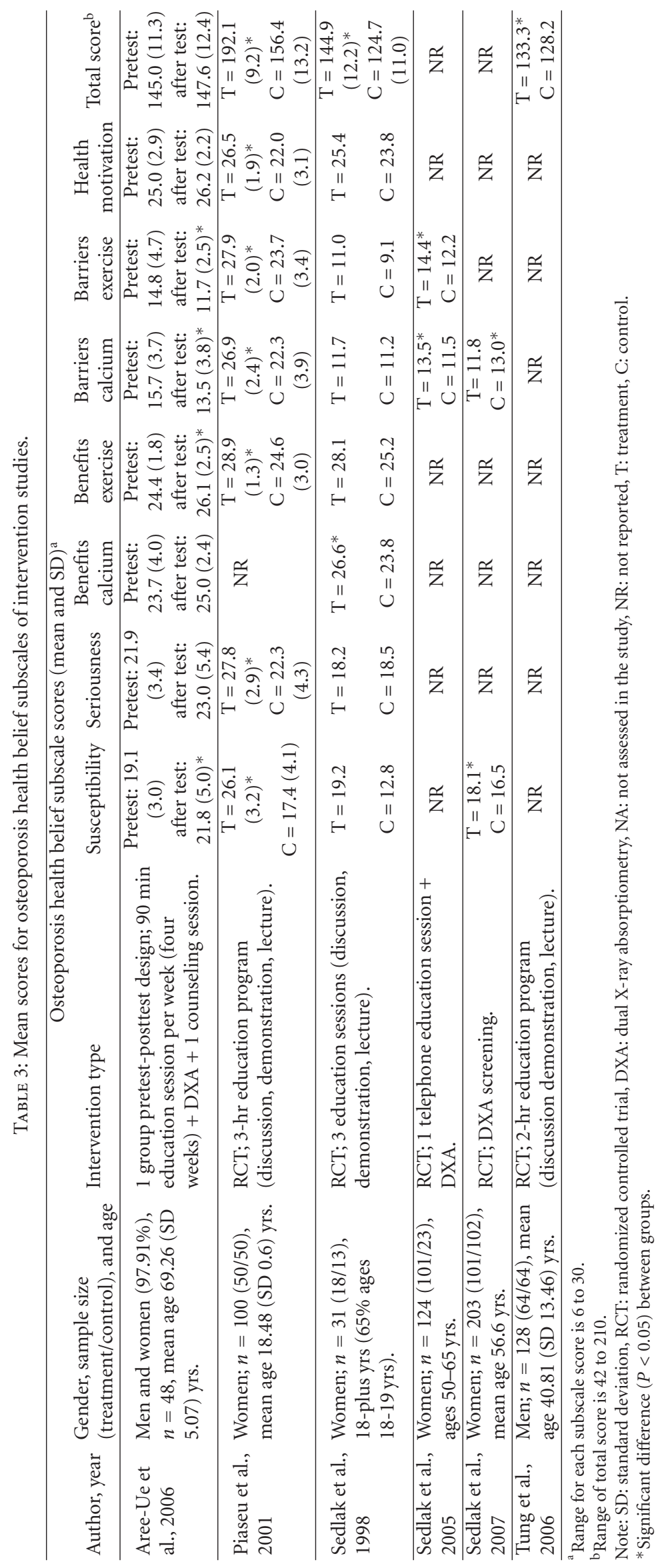


TABLE 4: Mean scores for osteoporosis self-efficacy subscales of intervention studies.

\begin{tabular}{|c|c|c|c|c|c|}
\hline \multicolumn{6}{|c|}{ Osteoporosis self-efficacy subscale scores (mean and SD) } \\
\hline Author, year & $\begin{array}{c}\text { Gender, sample size } \\
\text { (treatment/control), and age }\end{array}$ & Intervention type & $\begin{array}{l}\text { Self-efficacy } \\
\text { calcium }\end{array}$ & $\begin{array}{l}\text { Self-efficacy } \\
\text { exercise }\end{array}$ & Total score \\
\hline \multirow[t]{2}{*}{ Piaseu et al., $2001^{c}$} & \multirow{2}{*}{$\begin{array}{l}\text { Women; } n=100(50 / 50) \text {, mean } \\
\text { age } 18.48 \text { (SD 0.6) yrs. }\end{array}$} & \multirow{2}{*}{$\begin{array}{l}\text { RCT; 3-hr education program } \\
\text { (demonstration, lecture, } \\
\text { discussion). }\end{array}$} & $\begin{array}{c}\mathrm{T}=94.0 \\
(8.6)^{*}\end{array}$ & $\begin{array}{c}\mathrm{T}=78.3 \\
(9.0)^{*}\end{array}$ & \multirow[t]{2}{*}{ NR } \\
\hline & & & $\begin{array}{c}C=65.5 \\
(14.2)\end{array}$ & $\begin{array}{c}C=57.7 \\
(13.7)\end{array}$ & \\
\hline \multirow[t]{2}{*}{ Sedlak et al., 1998b } & \multirow{2}{*}{$\begin{array}{l}\text { Women; } n=31(18 / 13), 18 \text {-plus } \\
\text { yrs ( } 65 \% \text { ages } 18-19 \text { yrs }) .\end{array}$} & \multirow{2}{*}{$\begin{array}{l}\text { RCT; } 3 \text { education sessions } \\
\text { (discussion, demonstration, } \\
\text { lecture). }\end{array}$} & $\mathrm{T}=460.2$ & $\mathrm{~T}=425.2$ & $\begin{array}{c}\mathrm{T}=885.4^{\mathrm{d}} \\
\quad(161.2)\end{array}$ \\
\hline & & & $C=465.8$ & $C=496.5$ & $\begin{array}{c}C=962.3 \\
(146.5)\end{array}$ \\
\hline Tung et al., 2006 & $\begin{array}{c}\text { Men, } n=128(64 / 64) \text {, mean age } \\
40.81(\text { SD 13.46) yrs. }\end{array}$ & $\begin{array}{l}\text { RCT; 2-hr education program } \\
\text { (discussion demonstration, } \\
\text { lecture). }\end{array}$ & NR & NR & $\begin{array}{l}\mathrm{T}=731.1^{\mathrm{d}} \\
\mathrm{C}=770.6\end{array}$ \\
\hline
\end{tabular}

${ }^{a} 12$-item subscale used; score ranges from 0 to 100 .

${ }^{\mathrm{b}} 12$-item subscale used; score ranges from 0 to 600 .

c21-item subscale used; score ranges from 0 to 100 .

${ }^{\mathrm{d}}$ Range of total score for 12 -item questionnaire is 0 to 1200 .

${ }^{\mathrm{e}}$ Range of total score for 21-item questionnaire is 0 to 2100 .

Note: SD: standard deviation, DXA: dual X-ray absorptiometry, NA: not assessed in the study, NR: not reported, T: treatment, C: control.

* Significant difference $(P<0.05)$ between groups.

by Sedlak et al. [17] higher scores were also reported in the treatment group for benefits of exercise, barriers to calcium and exercise, and health motivation compared to the control group, however, the results were not significant. They did find a significant difference $(P<0.05)$ between groups for perceived benefits of calcium intake; however, no other trial reported results of this subscale to make a comparison. Similar to findings by Piaseu et al. [14], two studies in older men and women found perceived susceptibility and benefits to exercise significantly increased $(P<0.05)$ after intervention $[16,19]$. However, contrary to findings by Piaseu et al. [14], there was a significant decrease $(P<0.05)$ in perceived barriers to calcium and exercise $[16,19]$. The only intervention study involving only men (mean age 40.81 years) also showed a significant difference $(P<0.05)$ between groups with total treatment and control scores of 133.3 and 128.2, respectively.

Use of the OSES in intervention studies was limited as shown in Table 4. After a three-hour education program, Piaseu et al. [14] found that young women were more likely to have greater self-efficacy of calcium intake and exercise $(P<0.05)$ compared to those who did not receive the program. Contrary to these results, Sedlak et al. [17] reported lower OSES scores of young women receiving a three-hour education program compared to those in the control group; however, the results were not significant. In addition, the same trial that assessed OHBS outcomes in men showed total treatment and control scores of 731.1 and 770.6, respectively, but results were not significant.

\section{Discussion}

This is the first known systematic review of common osteoporosis health beliefs, as measured by the OHBS and OSES, in adult men and women from both descriptive and intervention studies. The principal finding from descriptive studies showed individuals generally have low to moderately high perceived susceptibility, moderate to high perceived seriousness, health motivation, and self-efficacy of calcium intake and exercise, high perceived benefits of calcium intake and exercise, and low to moderate barriers to calcium intake and exercise. While these studies have shown the OHBS is a promising tool for measuring health beliefs, it has not undergone extensive scrutiny particularly with regard to its factor structure and reliability in different populations [28]. There remains a great deal of uncertainty regarding the generalizability of these measurement tools across populations, including various ethnicities, males, and age groups. Testing reliability and validity of these questionnaires prior to research is essential to reduce error, especially when study populations being assessed are different from those used in the development studies.

Notably, the majority of studies published using the OHBS and OSES evaluate health beliefs in women, with only seven descriptive studies [24-26, 28-30,34] and one trial [18] assessing men. It is only in the past decade that research has drawn attention to osteoporosis prevalence in men, which may account for the limited research in this area. This may also largely explain the differences in health beliefs between men and women. Comparing gender groups, overall, women were significantly more likely to perceive themselves as susceptible to osteoporosis and perceive greater benefits to calcium intake and barriers to exercise compared to men. They also perceived significantly fewer barriers to calcium intake, less health motivation, and less selfefficacy to exercise compared to men $[24,26,28]$. For example, Johnson et al. [28] found that men over 50 years of age had significantly lower perceived susceptibility scores compared to women over 50 years of age, supporting the notion that osteoporosis is perceived as a disease primarily 
affecting women, therefore, women may be more aware and knowledgeable than men about osteoporosis and related preventive behaviours. These results also suggest that men continue to be unaware of the importance of osteoporosisrelated health behaviours for prevention and management of the disease; despite being more confident in their ability to engage in exercise [24]. It is of interest to note that after DXA screening, $50.3 \%$ of men in the study by Doheny et al. [24] were diagnosed with either osteopenia or osteoporosis, indicating the need for increased awareness of osteoporosis risk in men.

While women perceived themselves as susceptible and understood the seriousness of the disease, they lacked health motivation, perceived more barriers to exercise, and lacked confidence to perform exercise for osteoporosis prevention compared to men. It may be that women are more knowledgeable about calcium intake and apt to modify this health behaviour than modify or initiate an exercise regimen which may be more difficult to do. However, Sedlak et al. [30] found that while men reported moderately high levels self-efficacy (OSE-calcium mean 67.7 and OSE-exercise mean 66.9), only one third reported engaging in weight-bearing exercise at least twice a week and had mean dietary calcium intake of $542.6 \mathrm{mg} /$ day, well below the adequate intake of $1200 \mathrm{mg} /$ day as recommended by Osteoporosis Canada [1]. These findings suggest the need for osteoporosis education in men, particularly with regard to preventive health behaviours.

In addition, older men and women ( $\geq 45$ years of age) perceived greater susceptibility, seriousness, and barriers to calcium and exercise than younger individuals. This finding is not surprising as osteoporosis is a disease primarily affecting older adults, and younger individuals may be more likely to engage in exercise and perceive few barriers to calcium intake such as cholesterol and digestion concerns. However, notably, Aree-Ue et al. [19] and Sedlak et al. [16] found barrier scores decreased significantly after education and DXA intervention in older men and women.

Osteoporosis health beliefs in men and women may impact decisions to change preventive health behaviours. Such beliefs may also provide useful information for targeting certain constructs of health belief perceptions of a population when developing osteoporosis interventions. Cline and Worely [23] identified barriers as the most common health belief subscale impacting osteoporosis-related health behaviours, and validation of the OHBS showed greater health motivation and fewer perceived barriers to calcium intake and exercise were the most important constructs in explaining exercise and calcium intake behaviours in older adults [12]. For example, women who perceived themselves as susceptible to osteoporosis and perceived many benefits and few barriers to calcium intake were more likely to use calcium and vitamin D supplements [23]. These results are consistent with the general HBM literature findings wherein perceived barriers and susceptibility are the most significant constructs influencing health behaviours $[11,36]$.

Since its development, several studies using the OSES have shown that self-efficacy of calcium intake and exercise are significantly related to calcium intake and exercise behaviour for osteoporosis prevention and management in women [27, 31, 33]. For example, Wallace [33] grouped young women based on their calcium intake and exercise (high versus low) and found that women who reported high calcium intake ( $\geq 1200 \mathrm{mg} /$ day $)$ and high exercise levels $(\geq 90 \mathrm{~min} / \mathrm{wk}$ ) were significantly more likely to have high self-efficacy of calcium intake and exercise. No studies were found that evaluated self-efficacy and its relationship to osteoporosis preventive behaviours in men.

Of the intervention studies reviewed, several showed improved outcomes; however, these results must be interpreted with caution. The lack of randomized controlled trials makes it difficult to draw meaningful conclusions, as such; a meta-analysis was not possible as the studies were too heterogeneous to pool. Differences between the trials for study quality and interventions were the primary sources of variability. Overall, results showed that women were significantly more likely to perceive themselves as susceptible to osteoporosis, perceive osteoporosis as a serious condition, and perceive greater benefits to calcium intake and exercise [14-17]. While Piaseu et al. [14] found women in the treatment group had significantly higher self-efficacy for calcium intake and exercise after intervention, Sedlak et al. [17] did not, showing self-efficacy increased in the control group. Despite undergoing similar education interventions, this discrepancy may be due to the low sample size $(n=31)$ and differences in age groups.

The overall goal of health education is to ensure that individuals or groups have an understanding of their current health status in order to make informed decisions and health behaviour changes to preventive disease. Understanding osteoporosis health beliefs outcomes after an education and/or screening intervention may help to tailor interventions to a specific population. However, more research is needed to determine the type and delivery of intervention that best influences health beliefs. Generalized education programs may not be appropriate for the specific needs of every individual. The one trial involving men, only reported total scores for the OHBS and OSES, and two studies involving postmenopausal women only reported susceptibility and barrier results after intervention making it difficult to draw conclusions about the usefulness of these interventions in these age groups.

Current research suggests that theoretically informed programs and interventions are more effective in changing health behaviour in research and practice than those developed without theoretical basis $[37,38]$. By considering the most common osteoporosis health beliefs, such as susceptibility, benefits, and barriers, when planning education interventions, we may better address the factors that lead to health behaviour change therein, improving prevention and management of the disease.

\section{Conclusion}

There is substantial empirical evidence supporting the use of HBM constructs as important contributors to the explanation and prediction of individuals' health behaviours. With regard to the OHBS and OSES, perceived seriousness, 
benefits, barriers, and self-efficacy of calcium intake and exercise, and health motivation appear to be the most common subscales in men and women, and explaining change in osteoporosis preventive behaviours, particularly exercise and calcium intake. Modifying the OHBS and OSES questionnaires to predict other health behaviours related to osteoporosis, such as vitamin D intake and drug therapy initiation would be beneficial in tailoring osteoporosis education interventions for both research and practice.

While interventions for changing osteoporosis health beliefs and behaviours may be useful in research and practice, more research in this area is needed. In particular, longitudinal, randomized controlled trials evaluating the influence of osteoporosis education combined with and without DXA-screening results is needed. Also, tailoring these interventions to target health belief perceptions of older men, postmenopausal women, young adults, or different ethnicities is necessary for health behaviour change within these groups. Osteoporosis health beliefs are modifiable, therefore, taking these into consideration when planning interventions or promoting health behaviours may help improve prevention of the disease and have long-term costsaving benefits for the health care system when compared to the costs associated with treating and caring for individuals who have already suffered a fracture.

\section{Acknowledgments}

The authors would like to thank Nana K. A. Bonsu for his assistance as an independent reviewer of articles for inclusion in the systematic review. K. M. McLeod's research is supported by a Canadian Institute of Health Research Doctoral Research Award in partnership with the Saskatchewan Health Research Foundation.

\section{References}

[1] Osteoporosis Canada, “About Osteoporosis," Retrieved, 2010, http://www.osteoporosis.ca/.

[2] A. A. Khan, A. B. Hodsman, A. Papaioannou, D. Kendler, J. P. Brown, and W. P. Olszynski, "Management of osteoporosis in men: an update and case example," Canadian Medical Association Journal, vol. 176, no. 3, pp. 345-348, 2007.

[3] R. Goeree, B. O’Brien, D. Pettitt et al., "An assessment of the burden of illness due to osteoporosis in Canada," Journal of the Society of Obstetrics and Gynaecologist of Canada, vol. 18, pp. 15-24, 1996.

[4] G. Ioannidis, A. Papaioannou, W. M. Hopman et al., "Relation between fractures and mortality: results from the Canadian multicentre osteoporosis study," Canadian Medical Association Journal, vol. 181, no. 5, pp. 265-271, 2009.

[5] L. Bessette, L. G. Ste-Marie, S. Jean et al., "The care gap in diagnosis and treatment of women with a fragility fracture," Osteoporosis International, vol. 19, no. 1, pp. 79-86, 2008.

[6] J. H. Dolega-Cleszkowski, J. P. Bobyn, and S. J. Whiting, "Dietary intakes of Canadians in the 1990s using populationweighted data derived from the provincial nutrition surveys," Applied Physiology, Nutrition and Metabolism, vol. 31, no. 6, pp. 753-758, 2006.

[7] I. Rosenstock, "Why people use health services," The Milbank Memorial Fund Quarterly, vol. 44, no. 3, pp. 94-127, 1966.
[8] J. E. Painter, C. P. C. Borba, M. Hynes, D. Mays, and K. Glanz, "The use of theory in health behavior research from 2000 to 2005: a systematic review," Annals of Behavioral Medicine, vol. 35, no. 3, pp. 358-362, 2008.

[9] I. Rosenstock, V. J. Strecher, and M. H. Becker, "Social learning theory and the health belief model," Health Education Quarterly, vol. 15, no. 2, pp. 175-183, 1988.

[10] K. Glanz, B. K. Rimer, K. Viswanath et al., Health Behaviour and Health Education: Theory, Research, and Practice, JosseyBass, San Francisco, Calif, USA, 4th edition, 2008.

[11] J. A. Harrison, P. D. Mullen, and L. W. Green, "A meta-analysis of studies of the health belief model with adults," Health Education Research, vol. 7, no. 1, pp. 107-116, 1992.

[12] K. K. Kim, M. L. Horan, P. Gendler, and M. K. Patel, "Development and evaluation of the osteoporosis health belief scale," Research in Nursing \& Health, vol. 14, no. 2, pp. 155163, 1991.

[13] M. L. Horan, K. K. Kim, P. Gendler, R. D. Froman, and M. D. Patel, "Development and evaluation of the osteoporosis selfefficacy scale," Research in Nursing and Health, vol. 21, no. 5, pp. 395-403, 1998.

[14] N. Piaseu, B. Belza, and P. Mitchell, "Testing the effectiveness of an osteoporosis educational program for nursing students in Thailand," Arthritis Care and Research, vol. 45, no. 3, pp. 246-251, 2001.

[15] C. A. Sedlak, M. O. Doheny, P. J. Estok, and R. A. Zeller, "Tailored interventions to enhance osteoporosis prevention in women," Orthopaedic Nursing, vol. 24, no. 4, pp. 270-278, 2005.

[16] C. A. Sedlak, M. O. Doheny, P. J. Estok, R. A. Zeller, and J. Winchell, "DXA, health beliefs, and osteoporosis prevention behaviors," Journal of Aging and Health, vol. 19, no. 5, pp. 742756, 2007.

[17] C. A. Sedlak, M. O. Doheny, and S. L. Jones, "Osteoporosis prevention in young women," Orthopaedic Nursing, vol. 17, no. 3, pp. 53-60, 1998.

[18] W. C. Tung and I. F. K. Lee, "Effects of an osteoporosis educational programme for men," Journal of Advanced Nursing, vol. 56, no. 1, pp. 26-34, 2006.

[19] S. Aree-Ue, L. Pothiban, B. Belza, K. Sucamvang, and S. Panuthai, "Osteoporosis preventive behavior in Thai older adults: feasibility and acceptability," Journal of Gerontological Nursing, vol. 32, no. 7, pp. 23-30, 2006.

[20] E. R. Bogoch, V. Elliot-Gibson, B. G. Escott, and D. E. Beaton, "The osteoporosis needs of patients with wrist fracture," Journal of Orthopaedic Trauma, vol. 22, no. 8, pp. S73-S78, 2008.

[21] S. M. Cadarette, D. E. Beaton, and G. A. Hawker, "Osteoporosis health belief scale: minor changes were required after telephone administration among women," Journal of Clinical Epidemiology, vol. 57, no. 2, pp. 154-166, 2004.

[22] L. Carlsson and C. S. Johnson, "Osteoporosis health beliefs and practices among Korean immigrants in Nova Scotia," Journal of Immigrant Health, vol. 6, no. 2, pp. 93-100, 2004.

[23] R. R. Cline and M. M. Worley, "Osteoporosis health beliefs and self-care behaviors: an exploratory investigation," Journal of the American Pharmacists Association, vol. 46, no. 3, pp. 356363, 2006.

[24] M. O. Doheny, C. A. Sedlak, P. J. Estok, and R. Zeller, "Osteoporosis knowledge, health beliefs, and DXA T-scores in men and women 50 years of age and older," Orthopaedic Nursing, vol. 26, no. 4, pp. 243-250, 2007.

[25] M. O. Doheny, C. A. Sedlak, R. J. Hall, and P. J. Estok, "Structural model for osteoporosis preventing behavior in 
men," American Journal of Men's Health, vol. 4, no. 4, pp. 334$343,2010$.

[26] J. O. Elliott, M. P. Jacobson, and B. F. Seals, "Self-efficacy, knowledge, health beliefs, quality of life, and stigma in relation to osteoprotective behaviors in epilepsy," Epilepsy and Behavior, vol. 9, no. 3, pp. 478-491, 2006.

[27] P. J. Estok, C. A. Sedlak, M. O. Doheny, and R. Hall, "Structural model for osteoporosis preventing behavior in postmenopausal women," Nursing Research, vol. 56, no. 3, pp. 148-158, 2007.

[28] C. S. Johnson, W. McLeod, L. Kennedy, and K. McLeod, "Osteoporosis health beliefs among younger and older men and women," Health Education and Behavior, vol. 35, no. 5, pp. 721-733, 2008.

[29] L. Y. Lee and E. K. Lai, "Osteoporosis in older Chinese men: knowledge and health beliefs," Journal of Clinical Nursing, vol. 15, no. 3, pp. 353-355, 2006.

[30] C. A. Sedlak, M. O. Doheny, and P. J. Estok, "Osteoporosis in older men: knowledge and health beliefs," Orthopaedic Nursing, vol. 19, no. 3, pp. 38-44, 2000.

[31] R. A. Swaim, J. C. Barner, and C. M. Brown, "The relationship of calcium intake and exercise to osteoporosis health beliefs in postmenopausal women," Research in Social and Administrative Pharmacy, vol. 4, no. 2, pp. 153-163, 2008.

[32] S. Tan, L. Ji, J. Tsai et al., "Greater osteoporosis educational outreach is desirable among Chinese immigrants in Chinatown, Chicago," Osteoporosis International, vol. 20, no. 9, pp. 1517-1522, 2009.

[33] L. S. Wallace, "Osteoporosis prevention in college women: application of the expanded health belief model," American Journal of Health Behavior, vol. 26, no. 3, pp. 163-172, 2002.

[34] K. L. Gammage, C. Francoeur, D. E. Mack, and P. Klentrou, "Osteoporosis health beliefs and knowledge in college students: the role of dietary restraint," Eating Behaviors, vol. 10, no. 1, pp. 65-67, 2009.

[35] S. L. Ziccardi, C. A. Sedlak, and M. O. Doheny, "Knowledge and health beliefs of osteoporosis in college nursing students," Orthopaedic Nursing, vol. 23, no. 2, pp. 128-133, 2004.

[36] N. K. Janz and M. H. Becker, "The health belief model: a decade later," Health Education Quarterly, vol. 11, no. 1, pp. $1-47,1984$.

[37] R. P. Grol, M. C. Bosch, M. E. Hulscher, M. P. Eccles, and M. Wensing, "Planning and studying improvement in patient care: the use of theoretical perspectives," The Milbank Quarterly, vol. 85, no. 1, pp. 93-138, 2007.

[38] S. M. Noar and R. S. Zimmerman, "Health behavior theory and cumulative knowledge regarding health behaviors: are we moving in the right direction?" Health Education Research, vol. 20, no. 3, pp. 275-290, 2005. 


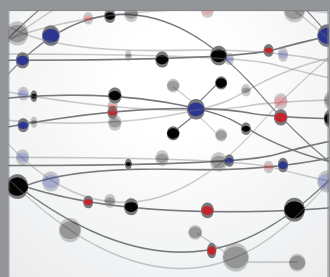

The Scientific World Journal
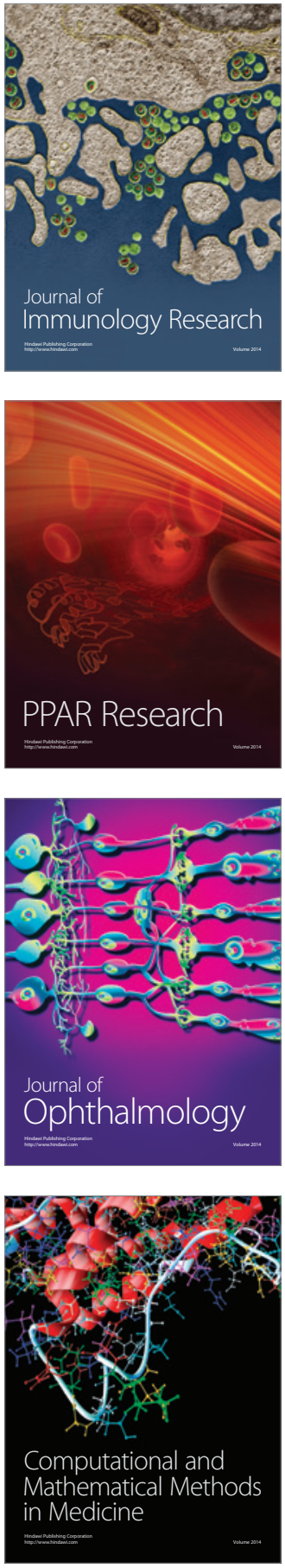

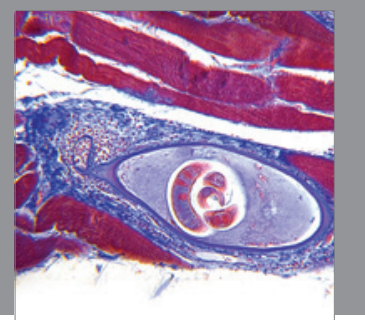

Gastroenterology

Research and Practice
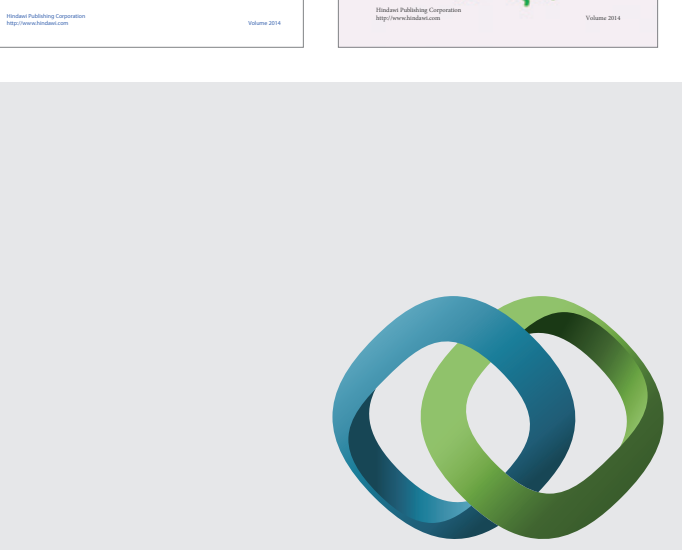

\section{Hindawi}

Submit your manuscripts at

http://www.hindawi.com
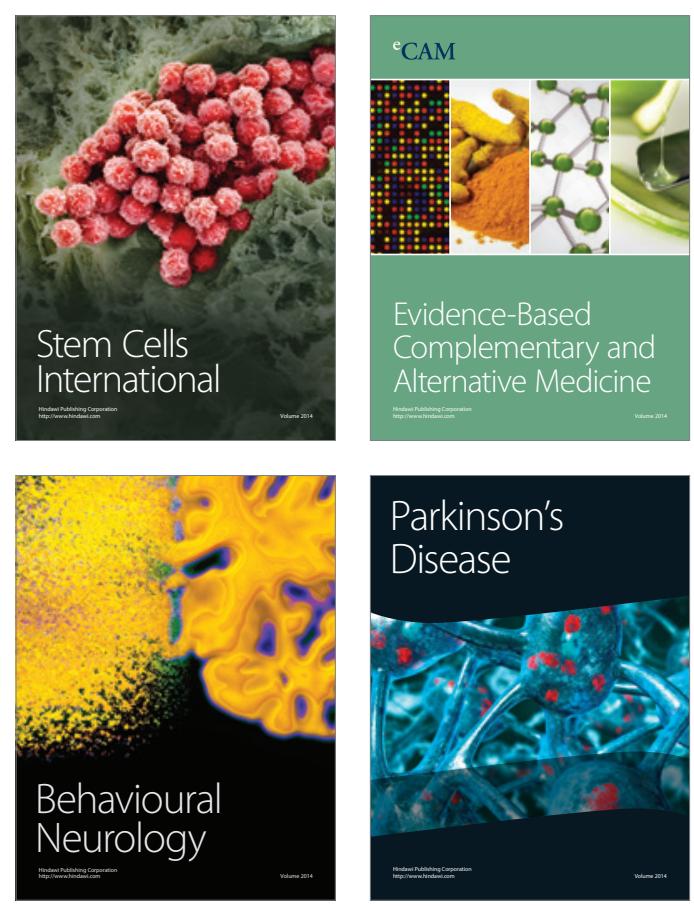

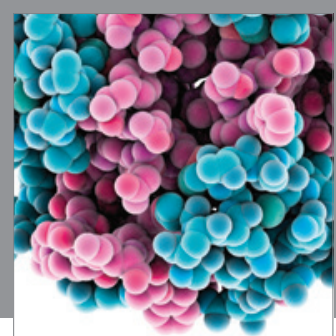

Journal of
Diabetes Research

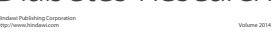

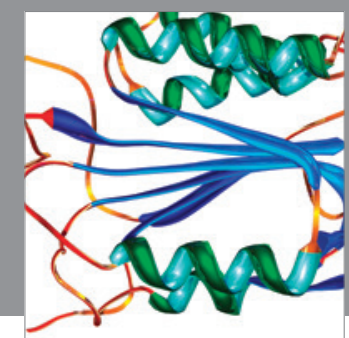

Disease Markers
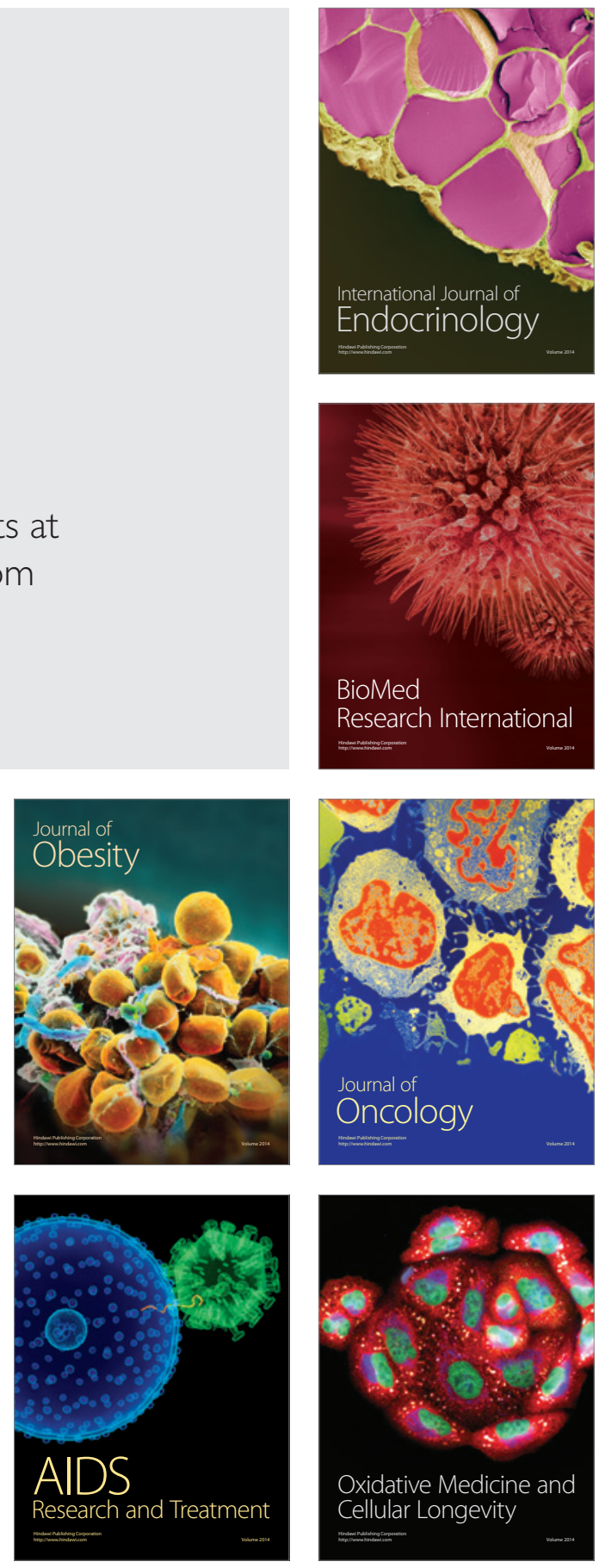